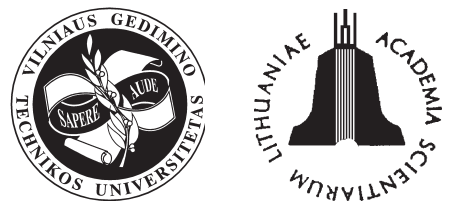

ISSN 1648-4142 TRANSPORT

www.transport.vtu.lt

\title{
ANALYSIS OF THE POSSIBILITIES OF BUILDING THE RAILWAY RAIL BALTICA IN LITHUANIA
}

\author{
Jonas Jonaitis ${ }^{1}$, Jonas Butkevičius ${ }^{2}$ \\ ${ }^{1}$ Vilnius Gediminas Technical University, Plytinès g. 27, LT-10105 Vilnius, Lithuania \\ ${ }^{1}$ E-mail: Jonas.Jonaitis@ti.vtu.lt²E-mai:vladas@ti.vtu.lt
}

Received 21 February 2005; accepted 25 June 2005

\begin{abstract}
The article deals with the objectives and possibilities of building the railway Rail Baltica through the Lithuanian territory, covers the alternatives of the choice of routes. In Lithuania's national transport policy the connection with Central and Western Europe by a direct, efficient and high-quality railway link has high priority. A significant chain of building a new chain is a bypass of Kaunas, therefore the alternatives of a bypass around Kaunas are being analysed. The article also presents the choice of location and types of stations, an alternative version of the route. The location of the stations was studied together with all other aspects of the new line (alignment parameters, travelling time, environmental impact and investment cost). It is recommended to considerably analyse possibilities to build the Rail Baltica route through Vilnius with a possible branch-line to Kaunas. Building of the route Rail Baltica is a technically complicated project, thus a focus is laid upon technical decisions.
\end{abstract}

Keywords: Fast railway, passenger and cargo shipping, market, AGC, AGTC, TINA, KLM.

\section{Introduction}

Railway transport in competition with road and air transport in the passenger transportation market has established a new type of railway - fast trains, the speed of which is over $260 \mathrm{~km} / \mathrm{h}$ [1].

In 1989 the International Railway Union (UIC) offered the Transport Committee of the European Economic Community to establish a common European fast railway system. The system of about 9000 $\mathrm{km}$ of fast railway lines is planned to be built in the European Economic Community countries till the year 2010 . Furthermore, about $15000 \mathrm{~km}$ of the existing railway lines are planned to be reconstructed into such new lines [2].

After Lithuania has entered the European Union, the development of the Lithuanian railways and their integration into the European railway network has become even more important. In Lithuania two European fast railway lines have been provided under the European fast railway development plan EURAILSPEED 95 1995, adopted by the International Railway Communication Organization the Congress in France. The first line will be: VarDuva - Kaunas - Ryga - Talinas/Helsinkis (I Crete transport corridor) and the second one: Klaipda - Kaunas - Odesa (IX Crete transport corridor). Priority is given to the first new fast railway line Warsaw - Helsinki, called the Rail Baltica which would cross four states - Poland, Lithuania, Latvia, and Estonia. This line is designated for the combined traffic - transportation of passengers and cargo [3].

Maximum speed of passenger trains will amount to $250 \mathrm{~km} / \mathrm{h}$, maximum speed of goods trains -140 $\mathrm{km} / \mathrm{h}$. Second class trains and lower speed trains will also be launched.

A new Rail Baltica route will be included into I corridor of the European fast railway development plan EURAILSPEED 95 I. The Rail Baltica is greatly significant for the Lithuanian economy and its building costs are huge, therefore the project decisions should be well thought-out and comply with the national interests [4].

\section{The analysis of versions of the route choices}

The railway line which is the subject of the present study can be divided into two subsections [5, 6]:

- Polish/ Lithuanian border - Mauručiai subsection $(68 \mathrm{~km})$. The alignment of this sub-section is already approved by the Government of the Republic of Lithuania.

- Mauručiai - Kèdainiai subsection (by-pass of 
Kaunas). Following three alignment alternatives were considered for this subsection:

- Eastern by-pass I $(75,5 \mathrm{~km})$. Crossing the river Nemunas over the Kaunas Sea dam and continuing northwards through Neveronys. Construction of a new interchange station in Palemonas.

- Eastern by-pass II (73,9 km). Crossing the river Nemunas over the Kaunas Sea dam and continuing northwards through Karmèlava. Construction of a new station close to Taikos Avenue (the station will only serve the new line, no interchange will be available).

- Western by-pass $(62 \mathrm{~km})$. Construction of a new $2024 \mathrm{~m}$ long viaduct to cross the river Nemunas. Construction of a new interchange station in Mauručiai.

The construction of the "Rail Baltica" is scheduled in several phases. The completion of phase 1 Warsaw - Kaunas is planned for 2010 . The following two options were studied for this phase:

- Polish/Lithuanian border - Mauručiai (73,5 km) and its connection to IX D Corridor in Mauručiai - Kaunas section.

- Polish/Lithuanian border - Palemonas (96,5 km) and its connection to IX D Corridor in the Palemonas station.

Financial and economic analyses (Internal Rate of Return, Net Present Value, Benefit/Cost ratio) were carried out in order to compare the alternatives from the financial and economical points of view. The following revenue sources were considered:
- Infrastructure usage charges paid by operators.

- Merging of the traffic from the road network to the railway:

- Reduction of the maintenance costs of the "Via Baltica" highway;

- Reduction of road traffic accidents.

- Merging of the traffic from the existing railway line to a new one:

- Reduction of the maintenance and operation costs of the existing line;

- Reduction of accidents on the existing line (e.g. on the level crossings)

while considering as costs:

- Capital investment costs:

- Construction costs;

- Land acquisition costs.

- Infrastructure maintenance and operation costs.

Table 1 summarises the results of the analysis of Phase 1 Polish/ Lithuanian border - Kaunas.

According to the results of technical studies as well as economic and financial assessments, taking into account the phasing of the whole "Rail Baltica" project by EC, the following solution is the most appropriate one for stage I of the "Rail Baltica" Line (Polish/Lithuanian Border - Kaunas):

- Construction of the Polish/Lithuanian Border Mauručiai new line section according to AGC and Interoperability requirements (Standard Gauge 1435 mm, 225 kN/axle maximum load, $160 \mathrm{~km} / \mathrm{h}$, etc.).

- Implementation of the Intermodal Logistic Cen-

Table 1. The results of the analysis of Phase I Polish/Lithuanian border - Kaunas

\begin{tabular}{|l|c|c|}
\hline & $\begin{array}{c}\text { South Connection } \\
\text { (Mauručiai) }\end{array}$ & $\begin{array}{c}\text { East Connection } \\
\text { (Palemonas) }\end{array}$ \\
\hline Length & $73,5 \mathrm{~km}$ & 96,5 \\
\hline Possible Extension in North Direction & West, East & East \\
\hline Interference with Existing Networks & Low & High \\
\hline Dependence on the Nemunas crossing & No & Yes (over the dam) \\
\hline Preparatory Documents Status: & & No \\
Preliminary Design & Completed 1997 & No \\
Territorial Plan & Completed & No \\
Environmental Impact Assessment & Completed & No \\
Detailed Design & No & 282 MEUR \\
Tendering & No & -177 MEUR \\
\hline Investment Cost & 185 MEUR & $-0,31 \%$ \\
\hline NPV (for 2040) & -96 MEUR & $0,74 \%$ \\
\hline EIRR & & \\
\hline \hline
\end{tabular}

NPV - Net Present Value, EIRR - Economical Internal Rate of Return. 
tre and its connection with the new "Rail Baltica" line and with the existing wide gauge line Kaunas - Kybartai.

- Connection of the new "Rail Baltica" line with the existing wide gauge line Kaunas - Kybartai. As the existent Lithuanian railway systems has a wide gauge $(1520 \mathrm{~mm})$ the implementation of the Gauge Changing Facility is necessary for the passenger services that will run from Warsaw to Vilnius.

For stage II of the "Rail Baltica" Line (Kaunas Lithuanian/Latvian Border) further studies should be carried out on the Lithuanian/Latvian cross-border point and the definition of the main alignment options for the Kaunas - Lithuanian/Latvian Border Section.

The construction of the new railway line cannot be afforded without Cohesion Fund co-funding.

\section{The purpose and preconditions of the project}

In Lithuania's national transport policy the connection with Central and Western Europe by a direct, efficient and high-quality railway link has a high priority. Moreover, the project is supported by EC politics on transport [7].

Protocol Agreement on Cooperation for the upgrading, reconstruction and development of Helsinki - Tallinn - Riga - Kaunas - Warsaw and Riga Kaliningrad - Gdansk Rail lines along the Crete Transport Corridor I was signed on 19 June 1997 in Paris by all the parties involved.

On 3 June 1999 Lithuania signed the Convention Concerning International Carriage by Rail (COTIF) in the version of the Protocol Modification of 3 June 1999. This document states that one of the aims of the Intergovernmental Organisation for International carriage by Rail (OTIF) is “...contributing to the removal, in the shortest time possible, of obstacles to the crossing of frontiers in international rail traffic, while taking into account special public interest, to the extent that the causes of these obstacles are within the responsibility of States".

In October 1999 the Final TINA Report was issued, describing the whole process and the up-to-date results. The line from the Polish/ Lithuanian border to Kaunas is identified in this report.

The Lithuanian Government and Municipalities have taken a decision for the alignment of the new line between the Polish border and Kaunas and Counties involved. The design prepared by Kaunas Transport and Road Research Institute was approved [8].

Agreed Minutes of Meeting between the Ministries of Transport of Poland and Lithuania regarding the joint development of Corridor I were signed on 13 May 1999.
On 1 October 2003 European Commission proposed adapting the guidelines for the trans-European transport network (TEN-T) to the dimensions of the enlarged European Union. Series of priority projects were proposed to be declared to be of European Interest. The document stated that "the extension of the major routes to the future Member States should help to make enlargement a success and provide the Union with a new opportunity to reduce congestion and encourage intermodality". This proposal includes the "Rail Baltica" line Warsaw - Kaunas - Riga Tallinn. The years for the completion of the work on different sections are the followings: Warsaw - Kaunas (2 010); Kaunas - Riga (2 014); Riga - Tallinn (2 016).

The project, for which a feasibility study was undertaken, consists of two components, i.e [9]:

1. New railway line from the Polish/ Lithuanian border to Kaunas;

2. Logistic and multimodal centre in Kaunas.

Both components of the envisaged project aim at improving traffic and in particular combined traffic, logistics and modal transfers along the TEN Corridor I, with a critical node in Kaunas area, where, after project implementation, the two railway systems would be interlinked at the important crossing of Corridors I and IX, the latter with a branch running from Klaipeda and Kaliningrad through Kaunas and Kiev to the Black Sea. For Lithuania, the other Baltic countries and Finland this major infrastructre project will determine major traffic flows in the long-term future through traffic generation and diversion from other modes of transport [10].

Presently, there is no an adequate railway link available from the Polish border to the North direction that forms a part of the TEN Corridor I from Helsinki through Tallinn, Riga and Kaunas to Warsaw. The cross-border railway section Mockava (Lithuania) - Trakiszki (Poland) currently used for the international rail traffic was closed up in the early nineties. Before the independence of Lithuania international traffic from Vilnius to Warsaw ran through Hrodna in Byelorussia.

By providing an appropriate link from Finland and the Baltic countries to Poland, Western and Southern Europe, this multimodal corridor will play an eminent economic and political role for the overall European integration and development and specifically for the integration of the Baltic countries in the trans-European rail network.

Different railway gauges in Western/Central Europe ("European standard gauge" or "UIC gauge" of $1435 \mathrm{~mm}$ ) and Eastern Europe including the Baltic countries and Finland ("Wide gauge" or "Russian gauge" of $1520 \mathrm{~mm}$ ) remain a major obstacle for allEuropean railway integration. 
At present international freight is reloaded in DeDtokai station from the WG wagons to the SG wagons.

This operation implies both additional costs and delay in the whole origin - destination route, thus makes rail freight transportation on the Corridor less competitive against other transport modes (mainly road and maritime traffic).

Regarding passenger traffic, an automatic gauge changing system developed by Polish railways for rail cars is installed at Mockava border station. This system represents substantial costs, travelling time and comfort advantages comparing to other traditional methods as bogie changing or passengers transfer from one train to another. However, due to the alignment of Marijampole - Mockava - Trakiszki - Suwalki Section travelling time for Vilnius - Warsaw trains is excessively high ( 9 hours for $653 \mathrm{~km}$, i.e. the commercial speed is $72,3 \mathrm{~km} / \mathrm{h}$ ) and discourages business travellers to use this transport mode.

The basic points already approved by the relevant authorities are the following:

- The cross-border connection will be located at the same point and on the same alignment as the existing cross-border connection on Mockava Trakiszki Section.

- The alignment approved (scale 1:2000) is the one named as Alternative 2 (closer one to Marijampole town). It is approved at kilometre 85.

However, the alignment by-passing the city of Kaunas raises two alternatives:

- $\quad$ East option. Continuing the alignment approved through Palemonas area and using the space available on the dam of the Kaunas Sea. The space available on the dam allows only one track. One 1520 (Russian) gauge track already exists on the dam. This alternative has two sub-alternatives.

- West option. Connecting with the alignment is approved at $\mathrm{km} 68$ approximately. This option is only possible in the case of the location of the intermodal centre in Mauručiai area. This option is 11,9 km shorter; however, $2024 \mathrm{~m}$ long viaduct over the river Nemunas will be needed.

Both of two options share the same alignment to $\mathrm{km} 68$ where the line is divided in two configurations mentioned above. As the new line will be European Standard Gauge it is intended to transfer the gauge changing device to its final location and to adjust/expand it to its final size and technique within the new overall system possibly in connection with the Logistic Centre in Kaunas area.

Two possible locations for the Kaunas Logistic Centre Construction were analysed. The locations initially considered for the assessment were the following:

- Mauručiai. This location was the recommended one in the previous studies.

- $\quad$ Palemonas. This location was proposed recently and had not been studied in-depth before.

Present Lithuanian railway transport sector, as well as the one in most of Eastern Europe countries, is rather behind modern, sophisticated and reciprocal Western and Northern Europe railway transport systems from a technical, economic and technological point of view.

While integrating the Lithuanian railway network into the European Union transport system, parameters of infrastructure elements have to satisfy the requirements of the international agreements AGC and AGTC at first. Rail construction elements and geometrical parameters have to be urgently regulated with the requirements of the European transport network.

European countries have created "International Railway Network" according to AGC protocol, confirmed in 1985 Geneva. In AGTC agreement, signed in 1991 in Geneva it is indicated to provide railway network "E" with multiplicity of equipment which would ensure the process of international composite inter-modal shipment. Such shipment enables to carry goods from door to door leastwise by two different kinds of transport.

According to AGC and AGTC agreements it was concluded that seeking to unify railway lines infrastructure parameters in European countries most parameters designed according to the requirements of these countries can remain. The most important infrastructure parameters according to AGC and AGTC agreements are presented in Table 2.

These requirements are applied for the modernisation lines which are incorporated into Transport Infrastructure Needs Assessment (TINA) program. The purpose of TINA is to estimate the needs of Middle and East Europe countries-Candidates to the European Union and to identify projects of common interests.

TINA network includes underlying of I and IX international railway transport corridors that pass Lithuanian territory. According to TINA, during the modernisation of the main railway lines it is necessary to follow the European Union directive 96/48/ $\mathrm{EB}$, defining trans-European high-speed railways system interaction.

According to this directive the whole railway infrastructure and rolling stock characteristics compatibility have to be insured in the whole trans-European transport network (TEN-T). 


\section{Proposed technical solutions}

The railway line starts at the Lithuanian - Polish border $(\mathrm{km} 0)$ as the continuation (in the same direction) of the existing line on the Polish side towards Mockava and Šeštokai. Some $3 \mathrm{~km}$ from the border station (New Mockava Station is located approx. at $3,6 \mathrm{~km}$ ), the new line turns left in the direction of Marijampole. The next approx. $25 \mathrm{~km}$ to Marijampole the line has very slight turns bypassing existing obstacles and built-up areas and includes a crossing station at $\mathrm{km} \mathrm{25,5.} \mathrm{The} \mathrm{alignment} \mathrm{crosses} \mathrm{at} \mathrm{the} \mathrm{eastern}$ side of Marijampole at the distance of 1-2 km. The line turns right into a north-eastern direction. New Marijampole station will be located approx. at km 40 .

From Marijampole the line goes almost straight and parallel to Via Baltica road at the distance of 2-3 $\mathrm{km}$ towards southern part of Kaunas. In this section a crossing station is foreseen approx. at $\mathrm{km} 56$.

The line keeps its north-eastern direction parallel to Via Baltica road to $\mathrm{km} 70$ where two alternatives are raised: either eastern by-pass or western bypass of Kaunas.

The line crosses the Nemunas River over the dam on the eastern side of the city. The dam at present incorporates a single track wide-gauge railway crossing used mainly for freight trains and a two-lane carriageway.

The dam was designed and constructed to support two railway tracks. The dam manager entity (Lietuvos Energija) was approached in order to confirm that the state of the foundation and the whole structure is appropriate for the installation of the second track. The received answer suggests that additional investigation is necessary in the case of the choice of this option.

When the dam is crossed two sub-alternatives can be chosen [11].

Eastern I variant alignment passes through Palemonas Station. It is foreseen to situate Kaunas Interchange Station at this station. This variant is approx. 1,6 km longer than the other variant because the residential area must be avoided. Both variants are joined at approx. $\mathrm{km} \mathrm{110.} \mathrm{From} \mathrm{this} \mathrm{point} \mathrm{the} \mathrm{align-}$ ment is the same for Kaunas eastern by-pass. The line turns left and continues in north-western direction to $\mathrm{km} 143,5$, at the vicinity of Kedainiai. Two crossing stations more will be located between Kaunas Interchange Station and the end of the line at $\mathrm{km} \mathrm{116,4}$ and 132 .

Easter II variant is the straight one. It travels through a nearer side to Kaunas and a viaduct should be built for it. Besides, this variant does not provide a suitable and feasible site to locate the Interchange Station. The station (Kaunas - Taikos Interchange Station) will be located at $\mathrm{km} \mathrm{95,8} \mathrm{and} \mathrm{will} \mathrm{only} \mathrm{serve}$ the new line. From this station the alignment turns right and left and continues in a north-western direction to $\mathrm{km} \mathrm{141,9.}$

Western alternative presents Mauručiai area as the only possible site to place KLN. The logistic centre will be located approx. from $\mathrm{km} 72$ to 74 .

From the New Interchange Station, the line continues in a northern direction, by western part of

Table 2. Railway infrastructure parameters according to AGC and AGTC agreements

\begin{tabular}{|c|c|c|}
\hline \multirow[t]{2}{*}{ Infrastructure parameters } & \multicolumn{2}{|c|}{ Requirements } \\
\hline & AGC & AGTC \\
\hline Number of roads & 1 or 2 & Not indicated \\
\hline Clearance of rolling-stock & UIC B & UIC B \\
\hline Minimal velocity, $\mathrm{km} / \mathrm{h}$ & 160 & 120 \\
\hline Distance between axes, $\mathrm{m}$ & 4 & 4 \\
\hline Permissible load to one linear meter, $\mathrm{t}$ & 8 & Not indicated \\
\hline \multicolumn{3}{|l|}{ Load to the axis: } \\
\hline Locomotives up to $200 \mathrm{~km} / \mathrm{h}$ & $22,5 \mathrm{t}$ & $22,5 \mathrm{t}$ \\
\hline Diesel and electric trains up to $300 \mathrm{~km} / \mathrm{h}$ & $17,0 \mathrm{t}$ & Not indicated \\
\hline \multicolumn{3}{|l|}{ Wagonloads: } \\
\hline up to $100 \mathrm{~km} / \mathrm{h}$ & $20,0 \mathrm{t}$ & $22,5 \mathrm{t}$ \\
\hline up to $120 \mathrm{~km} / \mathrm{h}$ & $20,0 \mathrm{t}$ & $20,0 \mathrm{t}$ \\
\hline up to $140 \mathrm{~km} / \mathrm{h}$ & $18,0 \mathrm{t}$ & Not indicated \\
\hline Maximum inclination, $\% o$ & Inclination is formed & Inclination is formed \\
\hline Minimal platform length in big stations, $\mathrm{m}$ & 400 & Not indicated \\
\hline Minimal bypass length, $\mathrm{m}$ & 750 & 500 \\
\hline Crossings & Not a single & Not indicated \\
\hline
\end{tabular}


Kaunas, with alignment parallel to Via Baltica road, although some kilometres far. Before crossing the Nemunas River one crossing station could be foreseen at $\mathrm{km} 86,8$.

It is necessary to construct a viaduct over the Nemunas River and Lampedis lake at $\mathrm{km} 88,6$.

A straight concrete bridge $2024 \mathrm{~m}$ long is proposed. It will have a gradient of $0,28 \%$ and a beam structure supported on two external bridge abutments and a series of pillars between the two abutments are suggested.

The railway track will be made of ballast, track, pavements and barrier. The bridge will have a span of $150 \mathrm{~m}$, and can be classified as a wide span viaduct. Box section beams will be used as they are the most effective from the point of view of resistance and they are those that best optimise the weight of the material. The width of the bridge floor has been established as $12 \mathrm{~m}$ and will be made of single cell box beams with constant depth, but the inertia will vary as the support is approached. This increase in inertia will be achieved by increasing the depth of the lower slab from the position $1 / 4$ to $1 / 5$ of the span away to the support.

The external spans will be between 0,25 and 0,75 of the central bridge span and in this case it will be the latter range.

The depth of the box section will be equal to $1 /$ 20 (following the length of the central span). There will be 14 circular pillars of variable height depending on the form of the terrain. Although there is no geo-technical information, it is expected that the foundations will be laid in low resistant stratas. The bridge pillars should be cemented onto piles on more resistant stratas.

For the crossing of the river two crossing stations are foreseen at $\mathrm{km} \mathrm{104,7} \mathrm{and} \mathrm{118,7.} \mathrm{The} \mathrm{new} \mathrm{line} \mathrm{goes}$ on to $\mathrm{km} 130$ (the end of the Project).

This alternative is $11,9 \mathrm{~km}$ shorter than the eastern alternative and this way to Kedainiai is much more straight than the other alternative alignment.

It is suggested that the railway will have to be constructed in stages. The first stage comprises:

- the construction of railway formation for two tracks;

- the laying of one track;

- the construction of road overpasses for the future two tracks;

- the construction of cattle crossings, culverts and drainage for the formation suited for the future two tracks;

- the construction of road and railway underpasses for one track;

- the construction of frontage roads and realignment of crossing roads according to the final two tracks;

- the construction of stations at the border $(\mathrm{km} \mathrm{3,6)}$ and at Marijampole $(40,25)$ and Crossing Stations at 25,9 and 56,122 ;

- the connection with KLN in Mauručiai area;

- the electrification of the line;

- initial maximum speed $160 \mathrm{~km} / \mathrm{h}$.

During the second stage the construction of the new railway line will be continued until the vicinity of Kedainiai. The construction of Kaunas Interchange Station and Crossing Stations according to the chosen alternative will be undertaken. At this stage technical parameter and conceptual design will be the same as the first one. This phasing of the construction meets the latest decision of the EC regarding the construction of the "Rail Baltica".

The new railway line is going to be constructed mainly in agricultural areas. It is proposed in the conceptual design that all road crossings are out of the level with the railway line. For connecting farmland on both sides of the railway line a number of cattle crossings are planned.

Road Overpasses. One type of bridge structure has been chosen for road underpasses and all crossings. All bridges have three spans with span lengths between $15 \mathrm{~m}$ and $27 \mathrm{~m}$ depending on the angle between road and railway at the crossing. In the middle span there is space for rail tracks. The side spans are for the slope of the embankment

The width of the road varies between $7 \mathrm{~m}$ and 10 $\mathrm{m}$ depending on the category of the road. On both sides of the road there is a sidewalk of $0,75 \mathrm{~m}$ wide.

The railway line is planned as a double track of the distance of $4,70 \mathrm{~m}$ between centres.

Road Underpasses. Two types of bridge structures have been chosen for the road underpass. One type is a box beam structure and the other is a T-beam structure. The bridges with box beam structure have three spans. The middle spans are between 13,50 and $16,50 \mathrm{~m}$ of length. The bridge with T-beam structure has three spans. The middle span is $23,60 \mathrm{~m}$ long. The side spans are for the slope of the embankment.

The bridges carry only one track. The overall width of the bridges is 5,30. The track is laid on ballast and the concrete slab is protected by a waterproofing membrane.

The width of the roadbed varies from $8,00 \mathrm{~m}$ to $11,00 \mathrm{~m}$ depending on the category of the road.

Railway Underpasses. There is one railway underpass. The bridge has four spans. Two middle spans are $16,50 \mathrm{~m}$ long. The superstructure is a box beam structure.

In one section under the bridge the existing double track railway line going from Marijampole to Šeštokai passes. In other section A road passes. The 
width of the roadbed is $8,00 \mathrm{~m}$.

River Crossings. There are four bridges crossing the rivers. All four bridges have three spans. Three bridges have a middle span with span length $23,60 \mathrm{~m}$. Two of them have side spans with span length 16,50 $\mathrm{m}$. One has side spans with span length $23,60 \mathrm{~m}$. The superstructure is a T-beam structure. One bridge has three equal spans with span length $9,30 \mathrm{~m}$. The superstructure is a box beam structure.

The river passes the bridge under the middle span. There is a path and the slope for the embankment in the side spans.

Cattle Crossings. All cattle crossings are of the same type. The crossings are designed as box tunnels. The length of the tunnels varies according to the depth of the tunnel under the railway tracks. The tunnels are designed for a double railway track passing over the tunnel.

For the detailed design of the bridges special attention shall be given to durability. All the structures are concrete structures. It is well known that concrete deteriorates during time depending on the severity of the environment.

To obtain durable structures the following main items should be considered during the design:

- The load carrying structures shall be designed with the lowest possible crack widths.

- Concrete shall be dense with low permeability and it shall be ensured that concrete does not contain materials which can reduce the durability.

- Concrete shall have a protective membrane or coating where concrete is exposed to severe environment.

Basically, the design of the new EG line follows AGC and AGTC standards for international corridors i.e.

- Track geometry for nominal minimum speed of $160 \mathrm{~km} / \mathrm{h}$.

- Axle load of $225 \mathrm{kN} /$ axle.

- Minimum platform length in principal stations of $400 \mathrm{~m}$.

- Minimum useful siding length of $750 \mathrm{~m}$.

ATGC standards will be applied without restriction for all technical options whereas AGC standards for the minimum solution as far as feasible.

To minimise time losses and to get maximum line capacity the preliminary design for crossing stations for the single-line option includes:

- The use of long switches (1 200-1:18,5) for 100 $\mathrm{km} / \mathrm{h}$ in turnout,

- simultaneous entry for trains in both directions with speeds $>=100 \mathrm{~km} / \mathrm{h}$.

In the same way level crossings (according to AGC Agreement) will be not built in order to achieve running time shorter and to avoid possible incidences.

For the connection of KLN with the existing wide gauge line quality criteria have been defined to allow trains with speeds $>=80 \mathrm{~km} / \mathrm{h}$ at the turnout thus minimising occupation time as follows:

- the use of long switches (R65 - 960-1:18),

- minimum radius $550 \mathrm{~m}$ with $\mathrm{u}=125 \mathrm{~mm}$,

- the distance between first turnout of the junction and entry point of the WG yard $>=1400 \mathrm{~m}$.

For the preliminary design platform heights have been used as shown below:

- $76 \mathrm{~cm}$ at Kaunas - Mauručiai Interchange,

- $25 \mathrm{~cm}$ at Mauručiai Gauge Changing Yard (emergency/service platforms),

- $\quad 38 \mathrm{~cm}$ at the other stations.

Further quality criteria for passenger trains will be defined as:

- minimum travelling speed for long-distance trains,

- minimum number of daily train pairs (cyclic schedule),

- 1 st/2nd class share, whether dining car service or not.

The traction power system shall be fed at a nominal $25 \mathrm{kV}$ AC and will be capable to provide safely and reliably supplying power through traction substations to the trains via an overhead contact system. The power supply system shall be designed to permit operation of trains hauled by $6 \mathrm{MW}$ locomotives.

The Overhead Catenary Line (OCL) shall be suitable for the specified operating speed and the local environment conditions.

Electrification of the general open tracks and of the stations on the line by means of autotensioned steady polygonal catenary are formed by independent tension-regulated catenary and contact wire.

The catenary on the open main lines will be designed for the speed of at least $160 \mathrm{~km} / \mathrm{h}$. It will be formed by autotensioned catenary.

The line will be equipped with the installation of various electronic interlockings in the stations across the line. A bidirectional automatic block system will be installed along the whole line in order to permit the movement of trains in both directions.

The signalling system is based on light signals along the side of the track which will indicate information on the current transit conditions to the train driver.

The signalling system will be controlled from a control centre where the central traffic and engineering control equipment will be installed.

The signalling system shall be able to operate in conjunction with the standardised ERTMS/ETCS Level 1.

GSM-R telecommunications system will be 
implemented on the line for train - ground communication. A digital communications system will be implemented. Fibre optic cables will be used as physical support for this communications system.

\section{The selection of the location and the types of the stations}

The passenger stations of the new line will be the following:

- Mockava,

- Marijampolè,

- Kaunas.

The location of the stations was studied together with all other aspects of the new line (alignment parameters, travelling time, environmental impact and the last, but not the least investment cost). Local aspects should also be considered: population evolution and its forecast, main economic sectors and their trends, railway and road infrastructure, mobility and accessibility to the predominant modal transport in the area, trends of development and present housing sector situation. All these aspects must be properly weighted according to the main objectives of the project.

The arrival of a high-speed train in a medium size city is seen as an opportunity of economic and social development. The city becomes suddenly more attractive and easily accessible and connected to other cities.

This new situation has been already experienced in other European countries during the last 30 years. Each of the cities has developed their own philosophy on how to combine this new train service and their specific urban needs.

At the same time some lacks in urban development that might be interesting to be considered can be found. The idea of Sprawl City is becoming stronger and the activity of old downtowns seems to be diminished.

There are several ways of regenerating social or economic activity in old downtowns. Even though it is linked to many other circumstances it is presumed that by studying this interaction between urban development and the location of train stations some clues for planning might be found. Remarks on the station situation in some European cities are presented above.

Regarding the position of the station with respect to the city centre the following five options could be considered [Fig]:

- Central Station. This solution is possible when the existing station and alignment are used and up-graded. Otherwise, in order to avoid a negative impact on the city tunnel construction is required. This option is the one used in big European cities and in some cases in medium ones, e.g. Würzburg, Fulda, Göttingen (all of them in Germany), Arezzo (Italy), Katrineholm (Sweden), Montbard, Puertollano (Spain).

- Boundary Station. This solution is similar to those adopted at the end of the nineteenth century when many of the nowadays existing stations were built-up. This solution was adopted for e.g. Ciudad Real station on the high speed line Madrid - Seville in Spain.

- Outskirts Station. This solution is similar to the precedent one. However, the station is more separated from the city centre. As examples of this solution following stations can be mentioned: Mâcon, Vêndome, Le Creusot, Valence (all of them in France) Guadalajara, Lleida (both on the high speed line Madrid - Barcelona in Spain), Puertollano (both on the high speed line Madrid - Seville in Spain). By means of a solid road network of the first level free of traffic congestion these station are connected with the town itself through convenient links. The new alignment solutions offer novel development in the surroundings of towns and cities. Besides, new areas which are normally reached by car and never on foot are created to permit to install industries, hotels, recreation areas and other services. The connection with the road in these stations is carried out by means of suitable links that have been designed to car access.

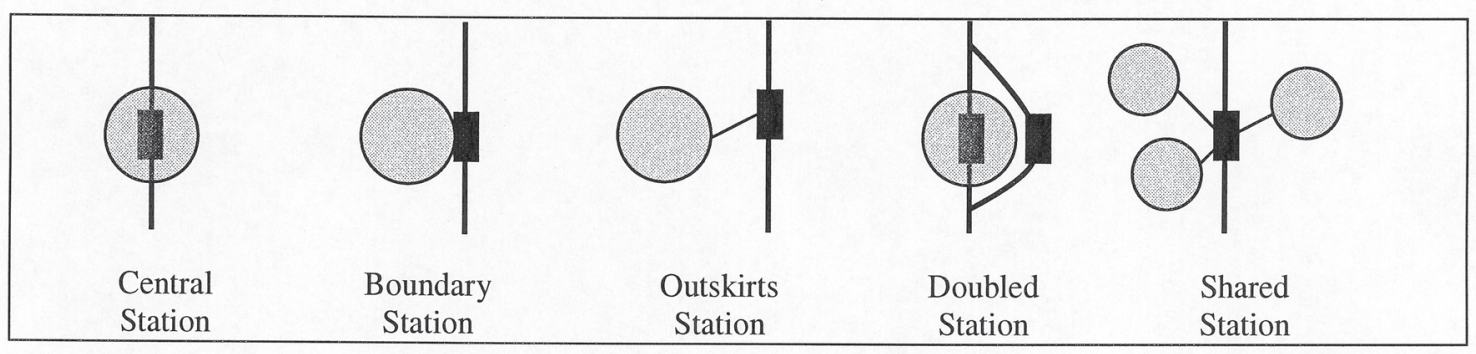

Different Concepts of Station Location 
- Doubled Station. Mixed solution combining the first option with either second or third one.

- Shared Station. This solution can be the appropriate one in areas with dense population distributed in several cities. In France the named this solution as "une gare au mileu dès bettraves", a station amidst the beetroots. As an example, the Haute Picardie station can be mentioned. This station is located between St. Quentin and Amiens and is distanced $25 \mathrm{~km}$ from both of them.

The solution finally proposed for each of the three stations is as follows:

- Mockava. Outskirts Station.

- Marijampolé. Boundary Station.

- Kaunas. The solution proposed for Kaunas could be considered as Doubled Station. However, the following remarks should be made:

- Two different gauge railway systems concur in Kaunas;

- The Central Station will remain as a wide gauge system station while the outskirts station will serve as an interchange station (from wide gauge to the European one and vice versa);

- The Central Station will be connected with the new line through gauge changing facility;

- In case of Western Alternative, outskirts station will serve the trains running from Riga and Tallinn to Warsaw, while the Central Station will serve the trains running from Vilnius to Warsaw;

- In the case of Eastern Alternative boundary station will serve the trains running both from Riga and Tallinn to Warsaw and from Vilnius to Warsaw.

The following considerations regarding the station location options named above lead to the new Kaunas station location proposed:

- Central Station. This option has been discarded due to the fact that from one hand it is necessary to maintain the existing wide gauge system and from the other hand, the construction of a new wide gauge track through the centre of the city is not economically feasible (new tunnel will be required).

- Boundary Station. In the case of Eastern by-pass a boundary station solution is adopted. The new line station will be located in either Palemonas or Taikos street area.

- Outskirts Station. In the case of Western by-pass a boundary station solution is adopted. The new line station will be located in Mauručiai area.

- Doubled Station. Mixed solution combining the first option with either second or third one.
- Shared Station. As there are no neighbouring cities of the similar population and importance as Kaunas, this solution is not considered.

Taikos street area is strongly non-recommended because of the absence of the possibility of interchange with the wide gauge railway system. The nearest station (Palemonas) is more than $1 \mathrm{~km}$ away.

It should be noticed that both Palemonas option and Mauručiai one will require to reach the station by means of public transport or private car both from Kaunas downtown and from the residential areas.

\section{The alternative version of the route}

In July, 2004 the country's Transit committee signed an agreement to build the fast railway through Kaunas and its introductory part to Kaunas - through Kaunas hydroelectric power station dam. According to the authors the latter decision is disputable in national security terms and from other points of view [12]. This solution is doubtful also due to the fact that the capital Vilnius is left aside from the fast railway. And the major flows of passengers are usually directed towards capitals. Furthermore, the Rail Baltica will combine capitals of three states - Warsaw, Riga and Tallinn, and Vilnius can be left out of the way. It is recommended to considerably analyse possibilities to build the Rail Baltica route through Vilnius with a possible branch-line to Kaunas.

The Rail Baltica Vilnius or Kaunas link route could be as follows: from Kaunas a railway is built beside IX D (up to Kaišiadorys), further - by the Russian track railway located beside IX B corridor, then it crosses near Vievis or Paneriai and reaches the southern Vilnius outskirts near the international airport. In future a railway route in Minsk direction is planned [13].

The Rail Baltica link with Vilnius is significant as this would ensure a fast and modern direct link of our capital with Europe. It could not be changed by 160 km/h Russian track Kaunas - Vilnius railway, the modernization of which is foreseen in future. For passengers a journey to Vilnius would become longer by 20 minutes and would not be so comfortable as compared with modern Rail Baltica trains. Besides, in Kaunas the Russian track railway station should be passed.

The Rail Baltica route in Vilnius could go through the northern airport bypass - a railway from Lentvaris would be built in the direction of Aukštieji Paneriai, before Vaidotai station it would cross the Russian track railway and through Raisteliai and Paneriai forest would end up near Žirniai street. In future, the railway would cross Lyda and Minsk highways and around the latter one would extend towards Minsk. 
Another variant - a bypass of the southern Vilnius airport - is also possible. The railway before Vaidotai station would cross the Russian track railway and through Raisteliai would reach Salininkai. In future, the railway would cross Lyda highway and, between Rudamina and Skaidiškès, would go through Medininkai to Minsk.

\section{The transportation of passengers by fast trains}

Having established a fast railway line Rail Baltica the Lithuanian railways will considerably increase their competitive ability in passenger transportation. Fast railway would take over [14]:

- from air transport - more than $80 \%$ of the market in routes to Warsaw, Riga, more than $50 \%$ of the market - in routes to Tallinn and $10-30 \%$ of the market - in routes to Berlin, Hamburg, Amsterdam, Paris;

- from buses - 40-50\% of the market in routes to Riga, Warsaw and 60-90\% of the market in routes to Tallinn, Berlin, Hamburg, Amsterdam, Paris;

- from private cars - 15-30\% of the market in routes to Warsaw and Riga and $40-60 \%$ of the market to Berlin, Tallinn, and etc.

\section{Conclusions}

1. The new EG line is only a part of the proposed Corridor I, and it will be interconnected with the Latvian, Lithuanian and Polish railway networks. The future situation on the adjoining sections must be considered.

2. The construction of the New Line shall be carried out in two stages.

3. The New Railway Line shall run for two kinds of transport: passenger and freight transport.

4. The design of the new EG line follows AGC and AGTC standards for international corridors.

5. The Overhead Catenary Line (OCL) shall be suitable for the specified operating speed and the local environment conditions.

6. It is purposeful to comprehensively analyse the possibility of building this line through Vilnius and only then to take a final decision whether a line should be built through Kaunas or Vilnius.

7. The introduction of the fast railway in Baltic states will enable them to successfully integrate into the European transport network. Furthermore, it will be a significant economic and social factor of Baltic countries development.

8. Building of fast railway will also revitalize the growth of the Lithuanian economy and the national business development.

9. The introduction of fast railway will enable to create new jobs in Kaunas (or Vilnius) and Šiauliai where passenger and cargo stations, intermodal terminal and logistics centres will be located.

\section{References}

1. European Union directive $96 / 48 / \mathrm{EB}$, defining transEuropean high-speed railways system interaction.

2. High - Level Group. The European High - Speed Train Network. 1995, p. 170.

3. Butkevičius, J.; Musteikis, J. Possibilities of Establishment of High-Speed Networks in Lithuania. Bulletin, Warsaw , 2002, No 6, p. 4-6.

4. Butkevičius, J. Development of Fast Railways in the World and Their Perspectives in Lithuania. Transport and Telecommunication, Vol 5, No 2, Riga, 2004, p. 105110.

5. Pre-feasibility studies for the European Gauge Railway Link from the Polish Border to Kaunas: GOPA-Consultants (Status Report, September 2000) and AB Kelprojektas and TRRI (Assessment Report, January 2003).

6. European standard railway line PL/LT border - Kaunas. Construction justification. Transport Road Research Institute (Lithuania), 1998.

7. Lithuanian Transport Ministry. The development of TEN I and IX corridors. OVE ARUP and Partners, 1996.

8. Obligatory Documents for Technical Design. Special Plan. Summary. Ministry of Transport and Communications of the Republic of Lithuania Transport Investment Directorate. Kaunas, 1999.

9. Jonaitis, J. European standard railway Rail Baltica. In: Proceeding of conference „Lithuania without Science - Lithuania without Future”. Transport. Vilnius: Technika, 2004, p. 244-249 (in Lithuanian).

10. Traffic Forecast on the TEN Pan-European Transport Corridors of Helsinki, NEA Company, Netherlands.

11. Jonaitis, J. Proposed Technical Solutions for Phase 1 of the Rail Baltica Project. In: Proceedings of international conference „Transport Means 2004". Kaunas: Technologija, 2004, p. 229-232.

12. Butkevičius, J.; Baublys, A. Development of Perspectives of Passenger and Cargo Transportation Across the Lithuanian-Polish Border. Vilnius: Technika, 2001, p. 26-30.

13. Šeduikis, A. RAIL BALTICA in Vilnius and Kaunas. Trasa, 2005.03.31, p. 13-15.

14. Butkevičius, J.; Žvirblis, A. The Rresearch on Passengers' Transportation by Land Transport and Formation of Formalized Models. Transport, Vol XVII, No 2, Vilnius: Technika, 2003, p. 84-88. 